University of St. Thomas, Minnesota

UST Research Online

2012

\title{
Effects of Increased Reporting Frequency on Nonprofessional Investors' Earnings Predictions
}

Terence Pitre

University of St. Thomas, Minnesota, pitr4066@stthomas.edu

Follow this and additional works at: https://ir.stthomas.edu/ocbacctpub

Part of the Accounting Commons

This Article is brought to you for free and open access by the Accounting at UST Research Online. It has been accepted for inclusion in Accounting Faculty Publications by an authorized administrator of UST Research Online. For more information, please contact asle4660@stthomas.edu. 


\section{Effects of Increased Reporting Frequency on Nonprofessional Investors' Earnings Predictions}

More frequent financial reporting has been a topic of debate for many years. However, little evidence exists about the possible effects of more frequent reporting on investors' decision making. Using a between-subjects experiment, this study analyzes how altering the timing or

frequency of earnings reports - weekly, as opposed to quarterly reports - affects the accuracy and dispersion of earnings predictions by nonprofessional investors. This is important since regulators have identified nonprofessionals as a significant audience for financial reports. I hypothesize and find that more frequent reporting results in less accurate predictions and greater variance, particularly when a strong seasonal pattern exists. Finally, investors in the more frequent reporting condition self-reported that they were more influenced by older historical data - suggesting primacy effects - while those in the less frequent reporting condition self-reported that they were more influenced by the newer historical data suggesting recency effects.

Keywords: disclosure frequency; earnings forecasts; accuracy; investor confidence. Data Availability: Data are available from the author on request. 


\section{INTRODUCTION}

Investors in securities markets search for information germane to making investment decisions. Earnings are clearly a primary variable of interest to the investment community. Investors view earnings with great interest since it represents a summary measure of performance and is believed to convey information about a firm's future cash-flow prospects (FASB, 1994 and Elliott, 2006). Further, market value can be expressed as a function of book value plus the present value of future expected abnormal earnings [Ohlson, 1995, p. 664]. Since expected abnormal earnings represents forecasted earnings reduced by a charge for capital, it is clear that predictions of earnings play a central role in explaining firm value under the Feltham and Ohlson (1995) model. As discussed by Bernard (1995, pp. 734-35), the work of Feltham and Ohlson reduces the importance of explaining stock price changes and emphasizes the forecasting of earnings.

Conventional wisdom suggests that the timely reporting of earnings is critical in financial decision making. This has been widely discussed in accounting. Yet, wide disparities in the timing of issuance of earnings reports persist: some European firms issue earnings reports semiannually, and have resisted attempts by regulators to require more frequent reporting (Commission 2003). At the other end of the spectrum, firms such as Cisco have already adopted the concept of real-time internal reporting, with the view that technologies such as XBRL (eXtensible Business Reporting Language) will make frequent external reporting a realistic possibility (Watson et al., 2000). In order to examine how more frequent reporting can affect investors and their decisions, I examine two extremes of financial reporting, weekly and quarterly. Specifically, this research compares the accuracy and variability of earnings assessments of nonprofessional investors that have access to weekly earnings reports with other 
nonprofessional investors that have access to quarterly earnings reports. ${ }^{1}$ Thus this research not only investigates whether more frequent reporting makes it harder for investors to detect earnings patterns, it also speaks directly to the more fundamental question of whether or not more frequent reporting in and of itself is more difficult to process by investors.

More frequent reporting of earnings is often seen as strictly advantageous to investors, and presumably, less frequent reporting is disadvantageous. One major benefit of more frequent reporting is the likelihood of more timely information provided to investors. ${ }^{2}$ Offsetting this benefit, however, are potentially negative effects of increased frequency on subjective judgment. Gneezy and Potters (1997) indicate and show that more frequent evaluations made possible by more frequent reporting of securities returns increased nonprofessional investors' impressions of the uncertainty of the returns, and more frequent evaluations of earnings may have similar effects. Benartzi and Thaler $(1995,1999)$ show that the frequency of reporting can affect the perceived uncertainty and volatility of an event leading to adverse effects on decision-making. More frequent reporting has already been shown to have adverse effects on management decision making (Bhojraj and Libby, 2005).

Moreover, larger data sets resulting from more frequent earnings reports could increase investors' cognitive load, decreasing the quality of decision making, and making it more likely that nonprofessionals will rely on simple heuristics (Schroder et al., 1967). Larger data sets may increase a number of judgment errors that have been demonstrated in the literature: failure to detect significant patterns in data series (Klayman, 1988), incorrect identification of patterns in

\footnotetext{
${ }^{1}$ This research should not be viewed a claim for or against weekly/quarterly reporting per se but rather as a theoretical tool for examining the benefits or costs of more/less frequent financial reporting.

${ }^{2}$ Other benefits have also been claimed for more frequent reporting. Hunton et al. (2003) argue that more frequent reporting of earnings would reduce the ability of managers to engage in earnings management and assist investors in detecting earnings management, because they would have more information to detect trends, patterns and fluctuations in earnings.
} 
particular data series (Maines and Hand, 1996), or the tendency to see patterns in a random series (Andreassen, 1987, 1990; Bloomfield et al., 2000; Lim and O'Connor, 1996; O'Connor et al., 1993). Nonprofessional investors, who are less likely to use sophisticated models to predict earnings, may be particularly vulnerable to such effects.

In this study, I experimentally examine how the frequency of earnings reports affects the accuracy and dispersion of earnings predictions of nonprofessional investors. Investor participants are randomly assigned to either the more frequent (weekly) or less frequent (quarterly) reporting conditions. The weekly earnings series were constructed so that the weekly earnings provided no statistical advantage or disadvantage in estimating quarterly earnings. ${ }^{3}$ Consequently, this study only measures judgment effects of more frequent reporting that are not due to differences in information content.

The results suggest that, holding information content constant, more frequent reporting leads to less accurate and more dispersed predictions of quarterly earnings. Additional analyses suggest that investors in both conditions demonstrated effects of heuristics when forming their predictions, consistent with previous findings from the Belief Adjustment Model (BAM) literature (Hogarth and Einhorn, 1992). Results also suggest that investors in the more frequent reporting condition were as confident in their judgments as those in the less frequent condition, despite being less accurate.

This study contributes to the regulatory debate, both in the United States and abroad, concerning the usefulness of more frequent reporting of earnings. This research can help decide

\footnotetext{
${ }^{3}$ Additionally, it is important to clarify that the more frequent reporting condition did not contain only noise, but in fact contained as useful/informative information as the less frequent reporting condition. Doing so specifically tests the predictability of more frequent reporting earnings data to that of less frequent reporting data. Additionally construction ensured that the prediction errors associated with the more frequent reporting condition are no different from those in the less frequent reporting condition. That is, even if participants failed to aggregate the weekly data (more frequent) into quarters, they could predict earnings with the same accuracy as those in the less frequent reporting condition.
} 
whether to impose more frequent, and potentially more costly, interim reporting. In fact, regulators and other interested parties in both the United States (Elliott, 2000) and Europe (IASC, 1996; Commission, 2003) have recommended that more frequent reporting be required or, at a minimum, encouraged.

Regulators and researchers have tended to focus on the benefits of more frequent reporting. This study suggests that there are potential costs to investors' use of frequent reporting and these costs should be incorporated into the debate. The findings of this research not only indicates that more frequent reporting leads to poor decision making, but also provide insight into how investors use more frequent reporting to make predictions. This research also contributes to the time series forecasting literature. While previous research has examined the effects of various factors in times series forecasting, the research has not examined how the frequency of reporting can affect forecasting judgments. ${ }^{4}$ Results in the archival capital markets research literature suggest that nonprofessional investors are less successful at incorporating the time series properties of earnings into their forecast than are professional investors (Abarbanell and Bernard, 1992; Jacob et al., 1999). Examining nonprofessional investors' judgments has the potential to add convergent validity to the results found in the capital markets literature as well as provide new insights into nonprofessional investors' use of time-series data.

The remainder of this paper is organized as follows. Section 2 is comprised of the literature review and hypotheses development, while Section 3 details the experimental design. Section 4 contains the empirical results, while conclusions and future directions are laid out in Section 5.

\footnotetext{
${ }^{4}$ See Webby and O'Connor (1996) for a review of judgmental and statistical time series literature.
} 


\section{LITERATURE REVIEW AND HYPOTHESES DEVELOPMENT}

The relative costs and benefits of increased reporting frequency have long been of interest to regulators, managers and investors. More frequent reporting may have negative effects on the subjective judgment of nonprofessional investors that may offset any potential informational benefits, and examining potential effects on judgment is a central question undertaken in this research. Next, theory from the subjective forecasting literature is used to motivate the hypotheses about specific effects of more frequent reporting on judgment accuracy and prediction dispersion.

\section{Effects of Increased Frequency on Accuracy}

It is important to understand how nonprofessional investors make earnings predictions since the price of a share is-or should be-determined by all investors' current expectations about the future values of variables that measure relevant performance and profitability, particularly earnings per share. Furthermore, as much as $42 \%$ of ownership in the top 1,000 U.S. companies is made up of nonprofessional investors (Editorial staff, 2000). Consequently, research has focused on nonprofessional investors' use of earnings reports to make judgments about future earnings, risk and firm value (Maines and McDaniel, 2000; Bartov et al., 2000; Maines and Hand, 1996). I discuss how investors can be affected by more frequent reporting by first assuming that investors can extract and use data perfectly-that is act in a perfectly Bayesian manner. I then assume that extraction and use is limited by individual ability (i.e., effort) and finally I examine what could happen if investors are susceptible to psychological biases such as recency or primacy effects. 


\section{Perfect Bayesian Rationality}

If investors behave in a perfect Bayesian manner, they would both extract and use all available information from the fundamental data in the same way, resulting in both high accuracy and little or no dispersion. Each investor would generate a forecast that will be the weighted average of their prior belief about earnings adjusted by their analysis of all of the available information. Investors would not focus on any one particular piece or aspect of the data. Additionally, in a perfect Bayesian world, it is assumed that the investor would not be susceptible to exogenous factors such as time constraints or fatigue. Therefore uninformative information would lead to no adjustment of prior beliefs, while informative information would lead to relatively extreme adjustments of prior beliefs. This is important since in this study the disaggregated data (more frequent reporting condition) would not result in any additional information content as compared to the aggregated data (less frequent reporting condition). That is, this study analyzes the impact of more frequent reporting when information content is held constant. Consequently, if investors behave as perfect Bayesians and accumulate and use the available data identically, there would be no forecast error and dispersion would be identical across individuals and subsequent groups.

\section{Bayesian Rationality Limited by Individual Differences and Ability.}

It is well known that the capacity of working memory is constrained. Due to individual differences and/or ability constraints, when nonprofessional investors process large quantities of data, they are not likely to consistently focus on the same subset of the data, resulting in incomplete or different data extraction (Bouwman, 1982). Incomplete or different data extraction means that investors will be differently informed by the same data (Kim and Verrecchia, 1997). Further, people often tend to see trends or streaks in truly random data series, 
but they do not all see identical trends or streaks (Andreassen, 1987, 1990; Bloomfield et al., 2000; Lim and O'Connor, 1996; O'Connor et al., 1993). Similarly, nonprofessional investors often incorrectly identify patterns in nonrandom data series. For example, Maines and Hand (1996) found that nonprofessional investors incorrectly detected autoregressive components in quarterly seasonal random walk data.

Three years of more frequently (weekly) reported data will include 156 earnings reports. Many nonprofessional investors will not be able to use all of this data. Consequently, they will differ with respect to how much of it they use and what conclusions they draw from it. As a result, earnings predictions are likely to be less accurate. Consider the identical seasonal data presented in both weekly and quarterly format in Figures 1 and 2 respectively.

----Insert Figure 1 about here----

The weekly fluctuations in the data in Figure 1 make it more difficult to discern the $4^{\text {th }}$ quarter earnings increase that is relatively clear in Figure 2.

----Insert Figure 2 about here----

The larger number of data points and more frequent changes of direction in the more frequent reporting condition present opportunities for individuals to see a greater variety of nonexistent patterns, as well as obscuring real patterns in the data that may exist.

Additionally, data extraction and use could be limited because it is time consuming and effortful. More frequent reporting will inherently require more effort by investors to aggregate and process the data. However, investors will only do so if the expected benefit outweighs the cost. As a consequence, the impact of each additional piece of information (specifically, the latter data pieces) could have a decreased impact on the prior beliefs resulting in adverse forecasts. Bloomfield and Hales (2009) posit and show that when financial incentives or rewards 
are not present, increased workload-such as that brought on by more frequent reporting-is likely to lead to effort aversion. However when financial incentives are present, those making predictions are likely to increase their effort. Specifically, they show that accuracy and dispersion are not affected when incentives are held constant across groups. Because incentives don't change as the task becomes more difficult, effort is likely to differ across conditions.

\section{HYPOTHESIS 1. Nonprofessional investors' absolute prediction errors} will be greater in the more frequent reporting condition than in the less frequent reporting condition.

Dispersion indicates to what degree the individual observations of a data set are dispersed or 'spread out' around their mean. Dispersion of expectations about earnings is important in practice because it can lead to increased trading volume. $\mathrm{H} 2$ focuses on dispersion alone. Summarily, the incentives to aggregate more data (decrease effort, save time, etc.), along with individuals using different subsets of data, will result in a larger dispersion in the more frequent reporting condition.

HYPOTHESIS 2. Variance of predictions will be larger in the more frequent reporting condition than in the less frequent reporting condition.

\section{Bayesian Rationality Limited by Psychological Biases}

Finally, Bayesian rationality may be adversely affected by different psychological biases. Two well known and documented biases are primacy and recency effects. The Belief Adjustment model (BA model hereafter) predicts that an individuals' attention to more recent pieces of information decreases as the amount of information increases in length leading to "a force towards primacy" (i.e., more weight is placed on earlier information). Shorter pieces of 
information, alternatively can lead to a "force towards recency" (more weight is placed on latter pieces of information). Hogarth and Einhorn (1992) predict that a force towards primacy occurs in "long" series of cues for two reasons: 1) individuals tire when tasked with processing large amounts of information, which causes them not be able to cognitively process the new information( referred to as attention decrement); and 2) as information accumulates, beliefs are expected to become less sensitive to the impact of new information since it represents an increasingly small proportion of the evidence already processed. Consequently, in the more (less) frequent reporting condition, participants are likely to be susceptible to primacy (recency) effects.

HYPOTHESIS 3. Nonprofessional investors' in the more frequent reporting condition will place more weight on earlier pieces of data (primacy effects), while Nonprofessional investors' in the less frequent reporting condition will place more weight on the latter pieces of data (recency effects).

\section{EXPERIMENTAL DESIGN}

\section{Experimental Design and Dependent Variables}

The experimental design is a 2 (quarterly vs. weekly reports) x 2 (earnings series) x 2 (increases vs. decreases between actual earnings and expected earnings [Foster model]). The variables are explained in Section 3.2 below. The three variables are manipulated between participants.

The dependent variables examined were 1) accuracy of predictions of next quarter's earnings, measured by the absolute difference between the prediction and earnings forecasted by the model and 2) dispersion of predictions, measured by the variance of investors' predictions. Hypotheses were tested by comparing judgment performance across frequency conditions. Using earning predictions as a dependent variable is preferred for several reasons. First, as 
stated earlier, earnings is a summary statistic preferred by investors and researchers due to its relation to both firm valuation and performance. Second, earnings estimates are preferred to other measures such as buy, sell or hold since the latter measures can be influenced by other factors such is existing positions, holdings, and/or leverage. Most importantly, being able to forecast firm performance (i.e., earnings) is the first step when evaluating a firm and subsequently deciding whether to buy, sell or hold. For example, an investor will likely buy (sell) a particular stock if he/she determines the firm is undervalued (overvalued) as measured by an earnings based estimate.

\section{Independent Variables and Data Construction}

The investors' task was to predict quarterly earnings per share based on historical data. As stated earlier, the ability to accurately predict earnings is important due to its direct relation to both cash flow predictions and to market valuation. In the more frequent reporting condition, investors received weekly historical earnings per share data. In the less frequent reporting condition, investors received quarterly historical earnings per share data.

Although technology will permit investors to easily view both forms of reporting, analyzing how investors use either more frequent or less frequent reporting is important for several reasons. It is possible that investors may believe that more frequently reported data is more informative than it actually is, or more recent. In addition, they may believe more frequent reporting to be more useful in making predictions between quarterly periods. However, because of individual cognitive abilities, some nonprofessional investors may opt to use the smaller, less cognitively demanding and less frequently reported data. They may also opt to use less frequently reported information if they are interested in making predictions with long term time horizons. Finally, it is important to initially understand how investors use either more or less 
frequently reported information because this provides evidence to the effects of more frequent reporting in the simplest setting, thus minimizing the cognitive load placed on investors. This also provides investors with the best opportunity to make accurate predictions and permits me to make stronger inferences about the effects of more frequent reporting.

To test the effects of more and less reporting frequency, I use earnings data with a seasonal pattern, generated from the Foster model. Both the quarterly and weekly data are seasonal and contain the same statistical properties. Since investors only see one type of data I am able to infer which format is more beneficial to investors in terms of forecast accuracy and dispersion. The Foster model is a relatively simple and effective earnings-prediction model that captures these seasonal effects.

$\mathrm{E}\left[\mathrm{Q}_{\mathrm{t}}\right]=\mathrm{Q}_{\mathrm{t}-4}+\delta+\varphi\left[\mathrm{Q}_{\mathrm{t}-1}-\mathrm{Q}_{\mathrm{t}-5}\right]$

Where: $Q_{t}=$ Quarterly earnings in current period.

$Q_{t-1}=$ Quarterly earnings one quarter prior

$Q_{t-4}=$ Quarterly earnings 4 quarters prior

$Q_{t-5}=$ Quarterly earnings 5 quarters prior

$\delta=$ the long run trend in year-to-year quarterly earnings increases.

$\varphi=$ year to year change in quarterly earnings experienced most recently $\left[\mathrm{Q}_{\mathrm{t}-1}-\mathrm{Q}_{\mathrm{t}-5}\right]$.

Initial quarterly earnings were those of Compaq Computer Company for the year 1993, which a widely used textbook employs as an example of earnings that can be predicted with the Foster model (Palepu et al., 1996). The Compaq data exhibited strong fourth quarter seasonality. The expected earnings in the subsequent quarter were generated using Compaq's values for the phi $(\boldsymbol{\varphi})$ parameter of .49 and the delta $(\boldsymbol{\delta})$ parameter of .09. The data was further extrapolated for an additional three years (12 quarters). This was done to remove any resemblance of actual earnings for the company. The data used in the experimental tasks consequently contained the 
statistical properties of the real data but did not contain any "real earnings" incurred by the company.

The data for each of the quarters was then evenly disaggregated into equal 13 weeks periods resulting in the following equation:

$\mathrm{E}\left[\mathrm{W}_{\mathrm{i}}\right]=\mathrm{W}_{\mathrm{it}-4}+\delta+\varphi\left[\mathrm{W}_{\mathrm{it}-1}-\mathrm{W}_{\mathrm{it}-5}\right]$

Where: $\mathrm{W}_{\mathrm{i}}=$ Weekly earnings in current week.

$\mathrm{W}_{\mathrm{it}-1}=$ The earnings in week i 1 quarter prior

$\mathrm{W}_{\mathrm{it}-4}=$ The earnings in week i 4 quarters prior

$\mathrm{W}_{\mathrm{it}-5}=$ The earnings in week i 5 quarters prior

$\delta_{\mathrm{w}}=$ Year-to-year weekly earnings increases.

$\varphi_{\mathrm{w}}=\mathrm{A}$ fraction of the year to year increase in weekly earnings experienced most recently[ $\left.\mathrm{W}_{\mathrm{it}-1}-\mathrm{W}_{\mathrm{it}-5}\right]$

A small amount of random error $\mathrm{N}(0, .01)$ was added to each week's earnings. The weeks were then subsequently added up into form 12 quarters. This created the two frequency conditions where the individual 13 week earnings represented the more frequent reporting condition and the aggregated 13 week earnings represented the less frequent reporting condition. In order to create additional instruments, the data stream was extended and a different overlapping 12 quarters were selected and the process repeated. In both conditions, the seasonality present was always in the same quarter. That is, there was no weekly seasonality to confuse participants. For example, if there was strong fourth quarter seasonality present in the quarterly (less frequent) data, then there was strong fourth quarter seasonality present in the weekly (more frequent) data. Further, the data was constructed such that prediction periods alternated between instruments. That is, the predicted period was upwards in some cases and downwards in other cases, but the fourth quarter seasonality was present in all eight versions of the instrument. This prevents investors from accurately predicting earnings by simply guessing 
or assuming the direction of earnings due to a preconceived idea or generalizations such as audit effects. $^{5}$

Each weekly instrument was tested to ensure that it contained the same information content as the less frequent or aggregated data. This was accomplished by taking the data from each weekly instrument and using regression to estimate the both the phi $(\boldsymbol{\varphi})$ and the delta $(\boldsymbol{\delta})$ parameters. Those parameters where then used to forecast the predicted quarter of interest. The same was done with the quarterly data and the two predictions were then compared to ensure that no significant differences existed. The underlying idea behind such testing was to ensure that that if participants in both groups processed the data as pure "statistical machines", they would reach the same predictions regardless of the reporting frequency condition. It is also worth noting that participants were given the data on a CD disk and each had a computer at their disposal. This way participants could aggregate the data, run any analysis they wished before making their predictions. Such measures biased against finding any results of adverse effects of more frequent reporting.

\section{Experimental Task and Procedure}

Investors received a packet along with an instruction sheet. Each packet contained a consent form, case materials, and a post-experiment questionnaire. The case materials informed investors that the most recent quarter end for the target firm was December 31, 2003. Investors were asked to predict earnings for the first quarter of 2004. In the more frequent reporting condition, a special caution was added to ensure that participants gave a quarterly and not a weekly prediction. Investors received earnings data in both tabular and graph form. In addition, a disk containing the tabular data in an excel spreadsheet was also given to the investors to aid in

\footnotetext{
${ }^{5}$ Audit effects describe a scenario where firms manage final quarter earnings upwards to make up for previous quarters shortfalls.
} 
calculations or reformatting of graphs if they desired. Experimental sessions took place in a computer lab, and all investors had access to spreadsheets. After making their predictions, investors were asked to generate the equivalent of $90 \%$ confidence intervals. See Appendices for examples of instruments.

At the conclusion of the prediction task, a post-experiment questionnaire was administered. Questions were included on investors' (1) stock market experience, (2) finance and statistical knowledge, (3) risk attitude, (4) judgments about the perceived volatility of the data, and (5) reports of the level of importance and influence of recent time periods in their judgments. The latter allowed for the identification of recency effects. Questions targeted at assessing the investors' comprehension of range and variance was also included in the post-experiment questionnaire. Finally, investors were required to describe in detail how they generated their prediction. Investors earned class credit for participation in the experiment. In addition, investors with predictions within $\$ .04$ of the actual earnings per share (20 in total) earned an additional $\$ 10$.

\section{Participants}

Participants in the experiment were 84 first and second year MBA students and Masters of Accounting students from a large state university in the Midwest. Participants were recruited from an MBA financial statement analysis class. Results from 12 participants were excluded because they generated weekly earnings predictions instead of quarterly earnings predictions, resulting in 72 participants being used in the analysis. Twenty-two (31\%) of the participants indicated they had investing experience, which ranged from one month to 84 months. The average number of university level finance courses taken was three and the average number of 
statistics courses taken by participants was two. The data was collected in one day with some participants attending a morning session while others attended an evening session.

\section{RESULTS}

\section{Overview}

Hypotheses 1 and 2 test the between-subjects effects of more frequent reporting on absolute prediction error and dispersion of predictions. H3 tests whether or not predictions were a result of either primacy or recency effects. ${ }^{6}$

\section{Test of hypothesis 1}

H1 states that nonprofessional investors' earnings predictions will be less accurate, as measured by their absolute prediction errors, in the more frequent reporting condition than in the less frequent reporting condition. Table 1 panel A reports the cell means and standard deviations. As expected, the absolute prediction error was larger $($ mean $=.14)$ with more frequent reporting than with less frequent reporting $($ mean $=.09)$. This difference was significant, as shown by the main effect of frequency in the ANOVA reported in Table 1, Panel B $(\mathrm{F}=4.04, \mathrm{p}<.05)$. There were also main effects of direction $(\mathrm{F}=15.83, \mathrm{p}<.00)$ and random error draw $(\mathrm{F}=25.16, \mathrm{p}<$ .00). However, there were no interactions involving these factors and frequency (all F's $<1.54$, p's > .22). These results provide support for $\mathrm{H} 1$.

----Insert Table 1 Here----

\footnotetext{
6 Although I did not hypothesize effects of direction of prediction or random error draw, ANOVAs revealed main effects of both these factors on prediction accuracy. However, neither direction of prediction nor random error draw interacted with the main variable of interest, frequency of reporting.
} 


\section{Test of Hypothesis 2}

$\mathrm{H} 2$ predicts that the dispersion of predictions will be larger in the more frequent reporting condition than in the less frequent reporting condition. Table 1, Panel C reports the variances of investors' earnings forecasts and results of the F-test for equal variances. The variance for the more frequent reporting condition (0.016) was greater than the variance for the less frequent reporting condition $(0.006, \mathrm{~F}=2.56, \mathrm{p}<.00)$. These results support $\mathrm{H} 2$.

\section{Test of Hypothesis 3}

$\mathrm{H} 3$ predicts that participants will exhibit effects of primacy in the more frequent reporting condition and recency effects in the less frequent reporting condition. Comparisons of the selfreported weights across conditions were conducted to identify the presence of recency or primacy effects. Table 1, Panel D shows that investors in the more frequent reporting condition reported a weight of 8.4 in the most recent period $\left(t^{-1}\right)$ while those in the less frequent reporting condition reported a weight of 18.2 ( $\mathrm{p}<.003$, not reported). Additionally, investors in the more frequent reporting condition reported a weight of 18.6 for the earliest quarter reported $\left(\mathrm{t}^{-12}\right)$ while those in the less frequent reporting condition reported a weight of $12.5(\mathrm{p}<.03$, not reported). These results suggest the presence of primacy and recency effects and are consistent with the BA model. ${ }^{7}$

\section{Supplemental Analyses}

Although the main effects of experience and the frequency * experience interaction are not significant, I compared the prediction errors of the more and less experienced participants to allay concerns that the effect of frequency might be largely dependent on less experienced

\footnotetext{
${ }^{7}$ I am unable to verify that participants did in fact place greater weight on early or late observations as a function of reporting frequency. Consequently the reader should interpret the results as only suggestive of primacy and recency effects.
} 
participants. Qualitatively, the analysis reveals that the difference between the frequency groups was greater for those participants who indicated they had investing experience. Here, experience is treated as a categorical, $0-1$ variable where 1 represents previous investing experience and 0 otherwise (in the ANOVAs used to test hypotheses, experience is included as a continuous variable, number of months of investing experience). For experienced participants the mean was .08 in the less frequent reporting condition and .14 in the more frequent condition. For inexperienced participants the mean was .10 in the less frequent reporting condition and .14 in the more frequent condition (not reported). Thus the results cannot be explained by a lack of investing experience.

Additionally, I also compared the confidence intervals generated by the participants to ensure predictions and dispersions were not adversely affected by greater perceived risk and/or difficulty. That is, if participants in the more frequent reporting condition perceived the reported earnings to be extremely risky and/or difficult to analyze, they would generate wider confidence intervals than those in the less frequent reporting condition. However, the mean confidence intervals were .57 for both the less and more frequent reporting conditions (not reported). Thus the differences in prediction accuracy and dispersion cannot be attributed to differences in confidence.

\section{CONCLUSIONS}

This study investigates the effects of more frequent reporting on nonprofessional investors' earnings predictions. As hypothesized, I find that more frequent reporting of earnings per share results in less accurate and more dispersed predictions of quarterly earnings per share. Analysis of self- reported data suggests that investors were influenced by recency or primacy effects. 
This study is subject to several limitations. First, I limited the amount of information investors received. Typically, when investors are evaluating the financial performance of a firm, more information is available and the information environment is more complex. However, reducing the complexity allows me to make stronger inferences about the effects of more frequent reporting. Second, this experiment uses MBA students as surrogates for nonprofessional investors. It is likely that they have less investment experience than many nonprofessional investors and therefore their actions may not accurately reflect the opinions of actual investors. Elliot, Hodge, Kennedy, and Pronk (2007) find that MBA students who have completed core courses and enrolled in or completed a course in financial statement analysis are a good proxy for nonprofessional investors in tasks low in integrative complexity. Integrative complexity is defined as the ability to draw relatively simple (complex) connections between distinct characteristics of the information set and subsequent judgments and decisions. Investors in this study had completed their core coursework, but had not completed nor where they enrolled in a financial statement analysis class. While the task in this study would likely be considered low in integrative complexity ${ }^{8}$, it is possible that the decisions of investors in this study could differ from those of nonprofessional investors. Third, this research examines the effects of investors using either more or less frequently reported information. Technology will make it possible for investors to view both forms simultaneously. It is possible that the presentation of more frequently reported information along with less frequently reported information could minimize the cognitive load making it less likely that investors will rely on heuristics such as recency or primacy. However, it is also possible that the investors may believe the more frequently reported data is more informative and superior to the less frequently reported

\footnotetext{
${ }^{8}$ The task in this experiment most closely resembles that of Maines and Hand (1996), which was classified as low integrative complexity by the Elliot et al. 2007.
} 
information leading to adverse processing effects. Finally, while weekly financial reporting is not currently implemented by firms, it is important to understand that the current research uses two extremes of financial reporting to illustrate possible implications from differences in financial reporting frequencies more so than to claim weekly data is worse than quarterly data per se. Consequently the design and results should be taken for their theoretical implications. Future research should examine if and how the joint presentation of more and less frequent reporting affects investor judgment. Finally, this experiment uses earnings data that contains fourth quarter seasonality which may not be applicable to all firms. Future research should investigate the effects of more frequent reporting when earnings data has different properties (i.g. random walk). 
FIGURE 1: More Frequent Reporting-Seasonal Data (partial table)

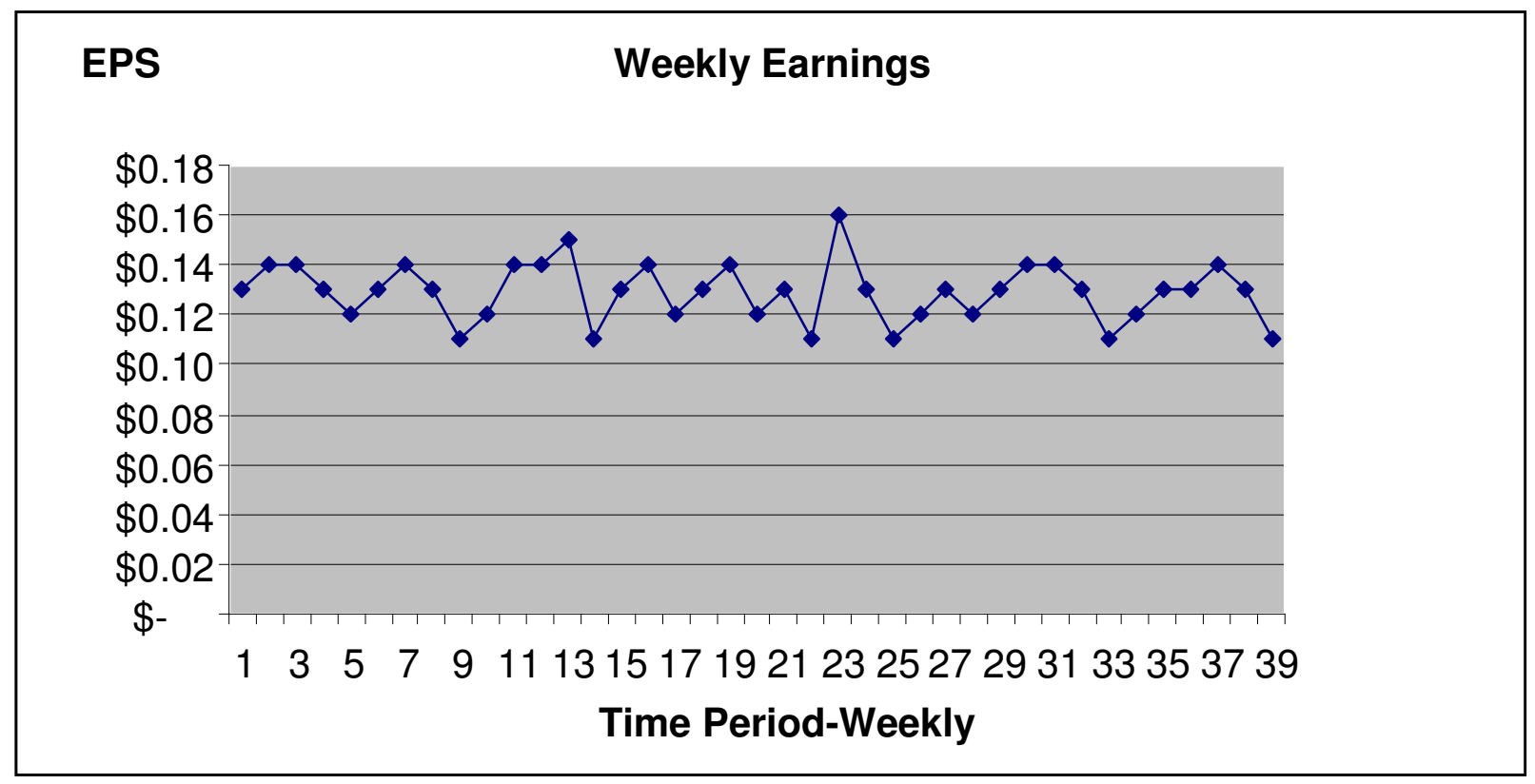


FIGURE 2: Less Frequent Reporting-Seasonal Data

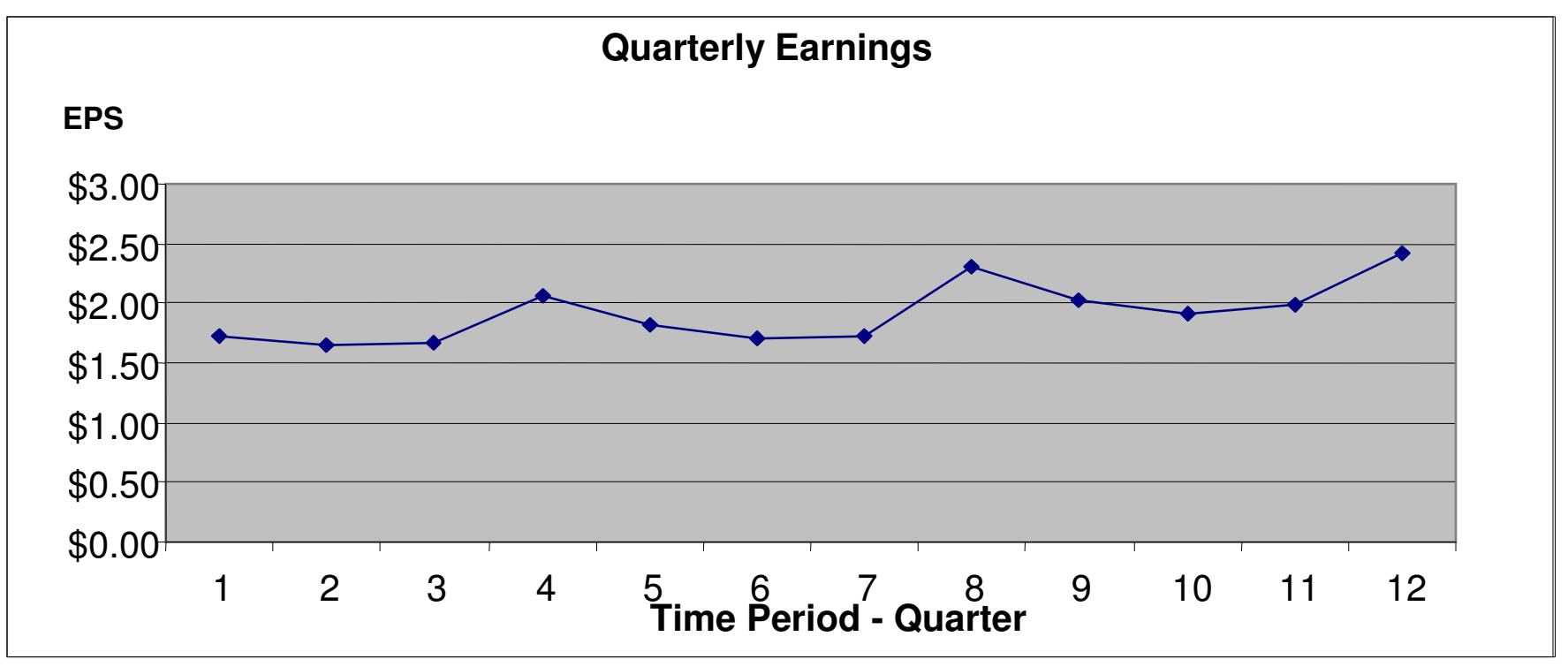




\section{Table 1}

Analysis of the Effects of More Frequent Reporting on Accuracy and Dispersion.

\begin{tabular}{|c|c|c|c|c|}
\hline Dependent Variable & $\underline{\text { Predict }}$ & tion error & $\underline{\text { Varia }}$ & \\
\hline Reporting Frequency & Less & More & $\underline{\text { Less }}$ & More \\
\hline Mean & 0.09 & 0.14 & ----- & ----- \\
\hline Median & 0.07 & 0.08 & ----- & ----- \\
\hline (s.d.)[Var] & $(0.08)$ & $(0.13)$ & {$[0.00$} & {$[0.016]$} \\
\hline $\mathrm{N}$ & 31 & 41 & 31 & 41 \\
\hline
\end{tabular}

Panel B: Test-H1-Between-Subjects ANOVA with Absolute Prediction Error as Dependent Variable $^{10}$

$\begin{array}{llrl}\text { Source } & \underline{\mathrm{df}} & \underline{\text { F-value }} & \text { p-value } \\ \text { Corrected Model } & 15 & 3.11 & .00 \\ \text { Intercept } & 1 & 100.89 & .00 \\ \text { Frequency } & 1 & 4.04 & .05 \\ \text { Direction } & 1 & 15.83 & .00 \\ \text { Rand.Error } & 1 & 25.16 & .00 \\ \text { Error } & 56 & & \\ \text { Total } & 72 & & \\ \text { Corrected Total } & 71 & & \end{array}$

Analysis of the Effects of More Frequent Reporting on Accuracy and Dispersion.

Panel C: Test-H2 -Between-Subjects Test with Variance as Dependent Variable.

\begin{tabular}{ll} 
Less Frequent $<$ More frequent reporting & $\frac{F \text { test }}{F=2.56} \quad \begin{array}{c}\mathrm{p} \text {-value } \\
\mathrm{p}<0.00\end{array}$ \\
\hline
\end{tabular}

Panel D: Descriptives: Self Reported Weights Reported

$\begin{array}{lll}\text { Less Frequency } & \frac{\text { Period t }^{-1}}{18.2} & \frac{\text { Period }^{-12}}{12.5} \\ \text { More Frequency } & 8.4 & 18.6\end{array}$

\footnotetext{
${ }^{9}$ Frequency = Frequency conditions between subjects: more and less reporting in forecasting tasks; Direction = Direction of change-upward or downward-between earnings in the last reported period and the forecasted period; Rand-Error $=$ Two different random error draws used to create earnings series.

${ }^{10}$ A complete ANOVA was conducted, Random error*direction significant at the $\mathrm{p}<.05$. There were no other variables or interactions significant at the $\mathrm{p}<.10$.
} 


\section{APPENDIX 1}

\section{Example of Less Frequent Reporting Instrument}

The current date is December 31, 2003. You own stock in ALPHA, Inc. and want to predict earnings per share for the next quarter (January - March 2004, a total of 13 weeks). The following pages contain a history of earnings per share for the past three years along with graphs to aid in your decision. You can review the pages in any order you desire and you can revisit pages if you desire. The disk contains a copy of the data tables presented below. The earnings data in the worksheet is protected and you cannot make changes to it. However, you can use the adjacent areas in the worksheet for any calculations you wish to make.

Based on the information provided on the following pages, please provide your best prediction of earnings per share for Quarter 1, 2004 [January 1, 2004 - March 31, 2004].

1. Your prediction of earnings per share is: $\$$

2. The actual earnings per share may not turn out to be exactly the same as you predicted in your answer to the previous question. But you probably have some idea of the range within which earnings per share is likely to fall.

With this in mind, please answer the following questions:

a. "I would be extremely surprised (no more than a 5\% chance of occurring) if next quarter's earnings were higher than $\$$ "

b. "I would be extremely surprised (no more than a 5\% chance of occurring) if next quarter's earnings were lower than $\$$ 


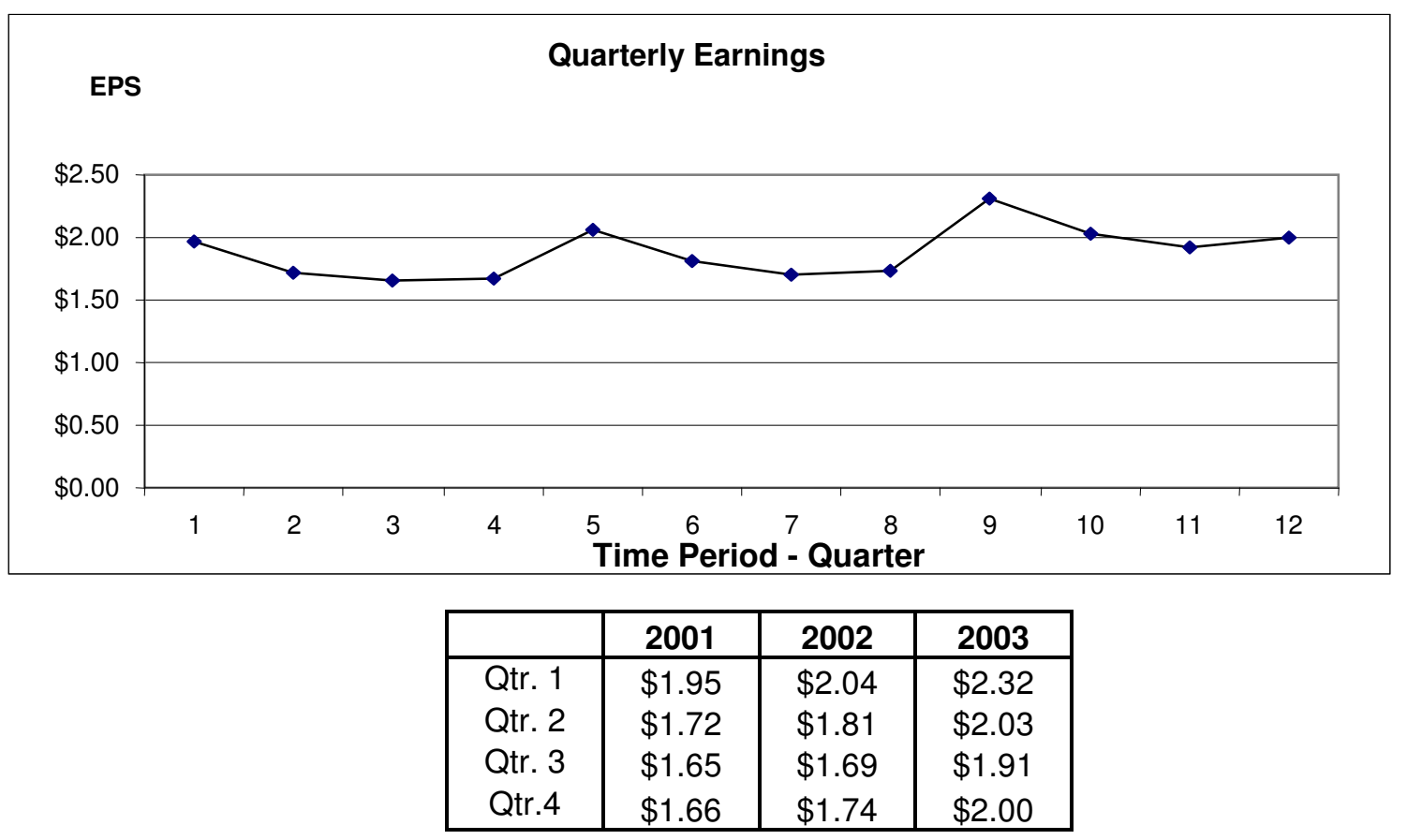




\section{APPENDIX 2}

Example of More Frequent Reporting Instrument

The current date is December 31, 2003. You own stock in ALPHA, Inc. and want to predict earnings per share for the next quarter (January - March 2004, a total of 13 weeks). The following pages contain a history of earnings per share for the past three years along with graphs to aid in your decision. You can review the pages in any order you desire and you can revisit pages if you desire. In the past, we have discovered that some students like to make calculations. Because we value your time, we have included a disk that contains a copy of the data tables presented below. The earnings data in the worksheet is protected and you cannot make changes to it. Although it is not required, you can use the adjacent areas in the worksheet for any calculations you wish to make.

Based on the information provided on the following pages, please provide your best prediction of earnings per share for Quarter 1, 2004 [January 1, 2004 - March 31, 2004].

3. Your prediction of earnings per share is: $\$$ (Please make sure you give a prediction for 13 weeks of earnings, not a single week)

4. The actual earnings per share may not turn out to be exactly the same as you predicted in your answer to the previous question. But you probably have some idea of the range within which earnings per share is likely to fall. With this in mind, please answer the following questions:

a. "I would be extremely surprised (no more than a 5\% chance of occurring) if next quarter's earnings were higher than $\$$ "

b. "I would be extremely surprised (no more than a 5\% chance of occurring) if next quarter's earnings were lower than $\$$ 


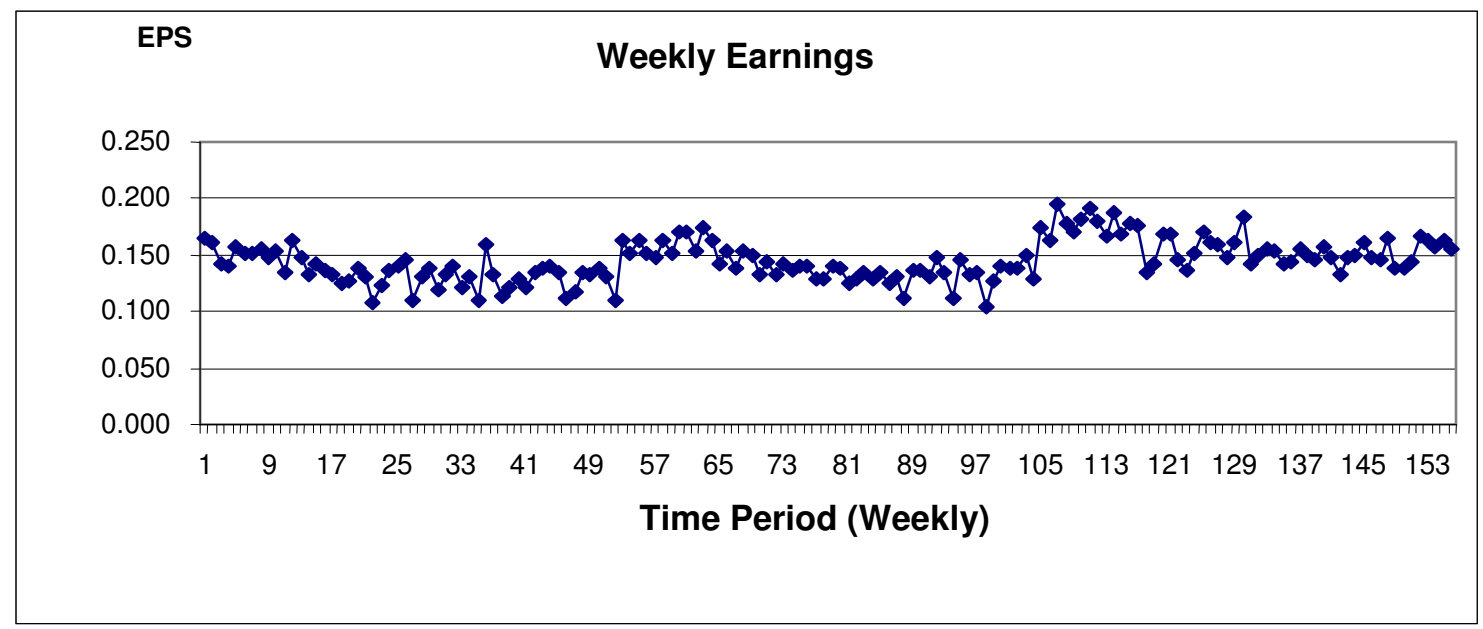

Year

2001

\begin{tabular}{|cccccccccc|}
\hline \multicolumn{2}{|c}{ Qtr. 1 } & \multicolumn{3}{c}{ Qtr. 2 } & & Qtr. 3 & & Qtr.4 & \\
1/1 & Week 1 & 0.16 & Week 14 & 0.13 & Week 27 & 0.11 & Week 40 & 0.13 \\
& Week 2 & 0.16 & Week 15 & 0.14 & Week 28 & 0.13 & Week 41 & 0.12 \\
& Week 3 & 0.14 & Week 16 & 0.14 & Week 29 & 0.14 & Week 42 & 0.13 & \\
Week 4 & 0.14 & Week 17 & 0.13 & Week 30 & 0.12 & Week 43 & 0.14 & \\
Week 5 & 0.16 & Week 18 & 0.12 & Week 31 & 0.13 & Week 44 & 0.14 & \\
Week 6 & 0.15 & Week 19 & 0.13 & Week 32 & 0.14 & Week 45 & 0.13 & \\
Week 7 & 0.15 & Week 20 & 0.14 & Week 33 & 0.12 & Week 46 & 0.11 \\
Week 8 & 0.15 & Week 21 & 0.13 & Week 34 & 0.13 & Week 47 & 0.12 & \\
Week 9 & 0.15 & Week 22 & 0.11 & Week 35 & 0.11 & Week 48 & 0.13 & \\
Week 10 & 0.15 & Week 23 & 0.12 & Week 36 & 0.16 & Week 49 & 0.13 & \\
Week 11 & 0.13 & Week 24 & 0.14 & Week 37 & 0.13 & Week 50 & 0.14 & \\
Week 12 & 0.16 & Week 25 & 0.14 & Week 38 & 0.11 & Week 51 & 0.13 & \\
Week 13 & 0.15 & Week 26 & 0.15 & Week 39 & 0.12 & Week 52 & 0.11 & $12 / 31$ \\
& & & & & & & & \\
\hline
\end{tabular}




\begin{tabular}{|c|c|c|c|c|c|c|c|c|c|}
\hline & Qtr. 1 & & Qtr. 2 & & Qtr. 3 & & Qtr.4 & & \\
\hline \multirow[t]{13}{*}{$1 / 1$} & Week 1 & 0.16 & Week 14 & 0.15 & Week 27 & 0.14 & Week 40 & 0.15 & \\
\hline & Week 2 & 0.15 & Week 15 & 0.14 & Week 28 & 0.14 & Week 41 & 0.13 & \\
\hline & Week 3 & 0.16 & Week 16 & 0.15 & Week 29 & 0.12 & Week 42 & 0.11 & \\
\hline & Week 4 & 0.15 & Week 17 & 0.15 & Week 30 & 0.13 & Week 43 & 0.15 & \\
\hline & Week 5 & 0.15 & Week 18 & 0.13 & Week 31 & 0.13 & Week 44 & 0.13 & \\
\hline & Week 6 & 0.16 & Week 19 & 0.14 & Week 32 & 0.13 & Week 45 & 0.13 & \\
\hline & Week 7 & 0.15 & Week 20 & 0.13 & Week 33 & 0.13 & Week 46 & 0.11 & \\
\hline & Week 8 & 0.17 & Week 21 & 0.14 & Week 34 & 0.12 & Week 47 & 0.13 & \\
\hline & Week 9 & 0.17 & Week 22 & 0.14 & Week 35 & 0.13 & Week 48 & 0.14 & \\
\hline & Week 10 & 0.15 & Week 23 & 0.14 & Week 36 & 0.11 & Week 49 & 0.14 & \\
\hline & Week 11 & 0.17 & Week 24 & 0.14 & Week 37 & 0.14 & Week 50 & 0.14 & \\
\hline & Week 12 & 0.16 & Week 25 & 0.13 & Week 38 & 0.14 & Week 51 & 0.15 & \\
\hline & Week 13 & 0.14 & Week 26 & 0.13 & Week 39 & 0.13 & Week 52 & 0.13 & $12 / 31$ \\
\hline
\end{tabular}

Year

2003

\begin{tabular}{|ccccccccc|}
\hline \multicolumn{1}{|c}{ Qtr. 1 } & \multicolumn{3}{c}{ Qtr. 2 } & & Qtr. 3 & & Qtr.4 & \\
1/1 & Week 1 & 0.17 & Week 14 & 0.13 & Week 27 & 0.14 & Week 40 & 0.15 \\
& Week 2 & 0.16 & Week 15 & 0.14 & Week 28 & 0.15 & Week 41 & 0.16 \\
Week 3 & 0.20 & Week 16 & 0.17 & Week 29 & 0.15 & Week 42 & 0.15 \\
Week 4 & 0.18 & Week 17 & 0.17 & Week 30 & 0.15 & Week 43 & 0.15 & \\
Week 5 & 0.17 & Week 18 & 0.15 & Week 31 & 0.14 & Week 44 & 0.16 \\
Week 6 & 0.18 & Week 19 & 0.14 & Week 32 & 0.14 & Week 45 & 0.14 \\
Week 7 & 0.19 & Week 20 & 0.15 & Week 33 & 0.15 & Week 46 & 0.14 \\
Week 8 & 0.18 & Week 21 & 0.17 & Week 34 & 0.15 & Week 47 & 0.14 \\
Week 9 & 0.17 & Week 22 & 0.16 & Week 35 & 0.15 & Week 48 & 0.17 & \\
Week 10 & 0.19 & Week 23 & 0.16 & Week 36 & 0.16 & Week 49 & 0.16 & \\
Week 11 & 0.17 & Week 24 & 0.15 & Week 37 & 0.15 & Week 50 & 0.16 & \\
Week 12 & 0.18 & Week 25 & 0.16 & Week 38 & 0.13 & Week 51 & 0.16 & \\
Week 13 & 0.18 & Week 25 & 0.18 & Week 39 & 0.15 & Week 52 & 0.16 & $12 / 31$ \\
& & & & & & & & \\
\hline
\end{tabular}




\section{REFERENCES}

Abarbanell, J. and V. L. Bernard. 1992. Test of Analysts'

Overreaction /Underreaction to Earnings Information as an Explanation for Anomalous Stock Price Behavior. Journal of Finance 47 (37): 11811208.

Alpert, M. and H. Raiffa. (1992). “A Progress Report on the Training of Probability Assessors" in D. Kahneman, P. Slovic and A. Tversky, eds., Judgment Under Uncertainty: Hueristics and Biases, Cambridge: Cambridge University Press.

Arnold, V., P. A. Caollier, S. A. Leech and S. Sutton. 2000. The effect of Experience on Order and Recency Bias in Decision Making by Professional Accountants. Accounting and Finance, 40: 109-134.

Andreassen, P.B. 1987. On the Social Psychology of the Stock Market: Aggregate Attributional Effects and Regressiveness of Prediction. Journal of Personality and Social Psychology 53: 490-496.

Andreassen, P.B. 1990. Judgmental Extrapolation and Market Overreaction on the Use and Disuse of News. Journal of Behavioral Decision Making 9 (4): 153-174.

Ball, R., and E. Bartov. 1996. How Naive Is the Stock Market's Use of Earnings Information? Journal of Accounting and Economics 21:319-337.

Bathke, A., and K. Lorek. 1984. The Relationship between Time-Series Models and the Security Market's Expectation of Quarterly Earnings. The Accounting Review 59:163-176.

Barber, B., and T. O'Dean. 2000. Trading is Hazardous to Your Wealth: The Common Stock Investment Performance of Individual Investors. Journal of Finance 55 (2): 773-806.

Bartov, E., S. Radhakrishnan, and I. Krinsky. 2000. Investor Sophistication and Patterns in Stock Returns after Earnings Announcements._The Accounting Review 75 (1): 43-63.

Benartzi, S. and R. Thaler. 1995. Myopic Loss Aversion and the Equity Premium Puzzle. Quarterly Journal of Economics 110 (1): 73-92.

1999. Risk Aversion or Myopia? Choices in Repeated Gambles and Retirement Investments. Management Science 5 (3): 364-381.

Bernard, V. L. (1995). The Feltham-Ohlson Framework: Implications for Empiricists. Contemporary Accounting Research, 733-747. 
Bhojraj, S., and R. Libby. Capital Market Pressure, Disclosure Frequency-Induced Earnings/Cash Flow Conflicts, and Managerial Myopia. The Accounting Review 80 (2005): 1-20.

Bloomfield, R., and J. Hales. 2002. Predicting the Next Step of a Random Walk: Experimental Evidence of Regime-Shifting Beliefs. Journal of Financial Economics 65 (3): 397-414.

2009. An experimental Investigation of the Positive and Negative Effects of Mutual Observation. The Accounting Review 84 (2): 331-354.

Bloomfield, R., W. Libby, and M. Nelson. 2000. The effects of Over-Weighting Old Elements of the Earnings Time Series. Working paper, Cornell University.

Bouwman, M. 1982. The Use of Accounting Information: Expert vs. Novice Behavior. In Decision Making: An Interdiciplinary Inquiry. G. Ungson and D. Braunstein,134-167 Boston, MA: Kent.

Brown, L. D. and M. S. Rozeff. (1979). Univariate Time-Series Models of Quarterly Accounting Earnings Per Share: A proposed Model. Journal of Accounting Research, 17, 733-747.

. (1993). Earnings Forecasting Research: Its Implication for Capital Markets Research. International Journal of Forecasting, 9, 295-320.

Commission of the European Communities. 2003. Proposal for a Directive of the European Parliament and of the Council on the Harmonization of Transparency Requirements with Regard to the Information About Issuers Whose Securities are Admitted to Trading on a Regulated Market and Amending Directive 2001/24/EC.

Daniel, K., Hirshleifer, D., and A. Aubrahmanyam. 1998. Investor Psychology and Security market Under-and Overreactions. The Journal of finance 53 (6): 227-248.

Editorial Staff. 2000. New Feature: Reversal of Fortune: Institutional Ownership Declining, Investor Relations Business:1 May: 8-9.

Eggleton, I. R.C., 1976, Patterns, Prototypes and Prediction: An Exploratory Study" Selected studies on Human Information Processing in Accounting. Supplement to Journal of Accounting Research, Vol. 14 pp. 68-131.

Eggleton, I. R.C., 1982, Intuitive Time Series Extrapolation. Journal of Accounting Research, Vol. 20, pp. 68-102.

Elliott, R., 2000. Hearing on Adapting a 1930's Financial Reporting Model to the 21st Century. Testimony before Senate Banking Committee: Subcommittee on Securities.

Elliott, W. B. (2006). Are investors Influenced by Pro Forma Emphasis and Reconciliations in 
Earnings Announcements? The Accounting Review, 81 (1), 113-133.

Elliot, W.B, F. Hodge, Jane Kennedy and M. Pronk. (2007). Are MBA Students a Good Proxy for Nonprofessional Investors? The Accounting Review 82 (1): 139-168.

Evans, C. (2003). Quarterly Reporting - Companies Face Quarterly Reporting Nightmare. Accountancy 132 (1322): 36-38.

Feltham, G. A. and J. A. Ohlson. (1995). Valuation and Clean Surplus Accounting for Operating and Financial Activities. Contemporary Accounting Research, 689-731.

Financial Accounting Standards Board (FASB). (1994). Statements of Financial Accounting Concepts: Accounting standards, Burr Ridge, Illinois, Irwin.

Foster, G. (1977). Quarterly accounting data: Time Series Properties and Predictive Ability Results. The Accounting Review, 52, 1-21.

Gervais, S. and T. Odean. (2001). Learning to be Overconfident. Review of Financial Studies 14:1-27.

, Heaton J.B. and T. Odean. 2002. The Positive role of Overconfidence and Optimism in Investment Policy. Working paper, University of Pennsylvania.

Griffin, D. and A. Tversky, 1992. The Weighting of Evidence and the Determinants of Confidence. Cognitive Psychology, 24, 411-435.

Griffin, P. (1977). The Time-Series Behavior of Quarterly Earnings: Preliminary Evidence. Journal of Accounting Research, 15, 71-83.

Gneezy, U. and J. Potters. 1997. An Experiment on Risk Taking and Evaluation Periods. The Quarterly Journal of Economics 112 (2): 631-645.

Heaton, J.B. 2002. Managerial Optimism and Corporate Finance. Financial Management 31 (summer): 33-45.

Hoge, R.D. 1970. Confidence and Decision as an Index of Perceived Accuracy of Information Processing. Psychonomic Science (18): 351-353.

Hogarth, R. M. and H. J. Einhorn. 1992. Order Effects in Belief Updating: The Belief Adjustment Model. Cognitive Psychology 24: 1-55.

Hunton, J., E. Wright and S. Wright. 2003. The Potential Impact of More Frequent Financial Reporting and Assurance: User, Preparer, and Auditor Assessments. The Journal of Emerging Technologies in Accounting, 4, pages 47-67. 
International Accounting Standards Committee (IASC), 1996. Interim Financial Reporting: An Issues Paper Prepared by the IASC staff

Jacob, J., T. Lys and J. Sabino. 1999. Autocorrelation Structure of Forecast Errors Time-Series Models: Alternative Assessments of the Causes of Post-Earnings Announcement Drift. Journal of Accounting and Economics 28(3): 329-358.

Kim, O. and R.E. Verrecchia. 1997. Pre-announcement and Event-period Private Information. Journal of Accounting and Economics 24 (3): 395-419.

Klayman, J. 1988. On The How and Why (Not) of Learning From Outcomes. Human Judgment: The SJT View, North Holland.

Levitt, A. 2002. Take on the Street: 2002 What Wall Street and Corporate America Don't Want You to Know. What You Can Do to Fight Back. New York: Random House.

Lim, J.S. and M. O'Connor. 1996. Judgmental Forecasting with Time Series and Causal Information. International Journal of Forecasting 12 (1): 139-153.

Lipe, M. 1998. Individual Investors' Risk Judgments and Investment Decisions: The Impact of Accounting and Market Data. Accounting Organizations and Society 23 (7): 625-640.

Maines, L. and J.R. Hand. 1996. Individuals' Perceptions and Misperceptions of Time Series Properties of Quarterly Earnings. The Accounting Review 71 (3): 317-336.

Maines, L. and L. S. McDaniel. 2000. Effects of Comprehensive-Income Characteristics on Nonprofessional Investors' Judgments: The Role of Financial Statement Presentation Format. The Accounting Review 75 (2): 179-207.

O’Conner, M., Remus, W. and K. Griggs. 1993. Judgmental Forecasting in Times of Change. International Journal of Forecasting 9 (2): 163-172.

Odean, T. 1999. Do Investors Trade too Much? American Economic Review 89 (5): 1279-1298.

Ohlson, J. A. (1995). Earnings, Book Values, and Dividends in Equity Valuation. Contemporary Accounting Research, 661-687.

Oskamp, S. 1965. Overconfidence in Case Study Judgments. Journal of Consulting Psychology 29: 261-265.

Palepu, K.G., P.M. Healy and V.L. Bernard. 1996. Business Analysis and 
Valuation Using Financial Statements: Text and Cases. Mason, Ohio: Thomson Southwestern.

Schroder, H. M., M.J. Driver and S. Streufert. 1967. Human Information Processing, New York: Holt.

Slovic, P. 1973. Behavioral Problems of Adhering to a Decision Policy. Working paper, Oregon Research Institute, Eugene Oregon.

Soffer, L. C, and T. Lys. 1999. Post-Earnings Announcement Drift and the Dissemination of Predictable Information. Contemporary Accounting Research 16:305-331.

Tversky, A. and D. Kahneman. 1974. Judgment Under Uncertainty: Heuristics and Biases. Science 185: 1124-1130.

Thaler, T., Tversky, A., D. Kahneman and A. Schwartz. 1997. The Effect of Myopia and Loss Aversion on Risk Taking: An Experimental Test. The Quarterly Journal of Economics 112( 2): 647-661.

Wallman, S. M. H. 1995. The Future of Accounting and Disclosure in an Evolving World: The need for Dramatic Change. Accounting Horizons 9 (3): 81-91.

Watts, R. (1975). The Time Series Behavior of Quarterly Earnings. Working Paper, University of Newcastle.

Watson, L., McGuire, L., and E. Cohen. 2000. Looking at Business Reports Through XBRL-tinted Glasses. Management Accounting 82 (3): 40-45.

Webby, R. and M. O'Conner. 1996. Judgmental and Statistical Time Series Forecasting: A Review of the Literature. International Journal of Forecasting 12 (1): 91-118. 